\title{
Predictive models in agricultural production
}

\author{
By C. T. de Wit ${ }^{1}$ and F. W. T. Penning de Vries ${ }^{2}$ \\ ${ }^{1}$ Department of Theoretical Production Ecology, Agricultural University, P.O. Box 430, \\ 6700 AK Wageningen, The Netherlands \\ ${ }^{2}$ Centre for Agrobiological Research, P.O. Box 14, 6700 AA Wageningen, The Netherlands
}

\begin{abstract}
Prediction may be envisaged as organized thinking about the possible. For this purpose, dynamic models of the state-variable approach are important tools because they combine basic knowledge on the physical, chemical and physiological processes that underlie crop growth and agricultural production. At one extreme are comprehensive models that claim to integrate all aspects of growth and to focus attention on the main gaps in present operational knowledge. As such, they are research tools. At the other extreme are summarizing models that are especially geared to answer 'what-if' questions and are used for evaluating regional production potentials and constraints, for irrigation management and integrated control of pests, diseases and weeds.

Examples of these types of models are given and their usefulness for predictive purposes is discussed.
\end{abstract}

\section{INTRODUGTION}

Dynamic models in agriculture are not new. Von Wulfen, a pupil of Thaer developed such a model of soil fertility and crop yield almost 200 years ago; this was based on many years of careful observations and some experimentation (see de Wit 1974). The answers given to 'what if' questions with these early models are simple and not very appropriate to specific cases.

Regression models, similar in nature, have been developed in much larger numbers, stimulated by the introduction of computers. However, they remain very specific and their refinement has not led to major improvements in accuracy or generality.

In the last 10-20 years, dynamic simulation models have been developed. These explicitly attempt to imitate mathematically the functioning of the crop. Such models are relatively simple representations of existing systems and contain interacting elements. A growing crop is such a system and its leaves and roots constitute some of the elements. If the system is not closed, its boundaries are ideally chosen in such a way that the environment influences the system, but not the reverse.

In spite of early expectations about the predictive power of simulation models, their evolution has been slow and their development is still far from complete. At present there are no predictive models if prediction is defined as the making of precise statements about the future. But even if we had fully satisfactory predictive models of crop growth these would not 'predict' in the above sense, because the weather is an unpredictable variable. To justify the title of this lecture, prediction is better defined as organized thinking about the possible. 


\section{DESGRIPTIVE MODELS}

As far'as modelling is concerned, two approaches can be taken: a descriptive or an explanatory one. In descriptive models, the system and its behaviour are described at the same level at which the observations about it were made. Examples are mathematical formulae that describe the growth curve of a crop and statistical analyses of crop-weather relations. After eliminating non-significant terms, the latter may lead to regression equations that relate yield to the temperatures and rainfalls in certain months or decades of the year in linear, quadratic and cubic terms.

This statistical 'blunderbuss' approach, to borrow a term of Monteith (198r), is not only clumsy, but also uninstructive because it ignores the underlying mechanisms and their interactions. At best, the results describe the existing situation, but they do not help organized thought about the possible. Descriptive models of crop growth, by their very nature, are therefore not tools for prediction as defined earlier.

\section{EXPLANATORY MODELS}

The second approach is the construction of explanatory models in which the processes that occur in the system form the basis of the model. It is not the behaviour of the system as a whole, but those of the underlying processes that are analysed and described, usually in a dynamic sense (de Wit 1970).

For example, to simulate the accumulation of biomass by a crop, the processes of $\mathrm{CO}_{2}$ assimilation, respiration, assimilate partitioning and leaf formation are considered. For each of these their dependence on environmental factors such as temperature and light on the internal status of the crop is quantified. The internal status of the crop is characterized by state variables such as the biomass of leaves and roots, their surface and architecture and their nitrogen content and turgidity.

With the model, the rates of these processes are calculated, given the current external conditions and the internal status. The biomass that is formed during a short time interval is computed as a rate multiplied by the length of the time interval and this is added to the biomass already present. Other relevant state variables are updated at the same time. The calculation is repeated again and again until the whole growth period has been covered.

Crop growth expressed in this way is thus explained on the basis of a broad knowledge of the underlying physiological, physical and chemical processes involved and the effects of environmental factors on them. It is typical that the behaviour explained and the explanatory processes are characterized by different relaxation times; indeed, they are often studied in different disciplines. Their use leads, therefore, to an integration of different fields of knowledge and such a broad base implies that explanatory models are potentially predictive tools. One must still be modest, however; only by comparing simulated results with the results of field experiments may sufficient confidence be built to attempt exploration of the possible.

\section{FROM COMPREHENSIVE TO SUMMARY MODELS}

The number of processes of primary importance necessary to simulate biomass accumulation by a field crop is relatively small and so is the amount of detail that is necessary to quantify them accurately. For example, it is not necessary for many purposes to compute the 
$\mathrm{CO}_{2}$ assimilation of each leaf minute by minute or each leaf layer hour by hour; it is sufficient to relate the daily $\mathrm{CO}_{2}$ assimilation to the daily irradiance, the leaf-area index and the photosynthesis light-response curve of a single leaf (Penning de Vries \& van Laar i 982).

This simplification eliminates the need to incorporate the biochemistry of photosynthesis in models of crop growth. Explanatory models can therefore operate satisfactorily in spite of the unavoidable incompleteness of our understanding of the fundamental processes. Obviously, the processes at the explanatory level should be properly quantified, but it is of little importance whether these processes themselves are 'described' or 'explained'. Of course, the processes themselves may be modelled in an explanatory fashion in their own right, but this is another matter. Attempts to construct models that contain so many levels of explanation that the behaviour at the population level is explained on the basis of knowledge at the molecular level do not serve any purpose.

Large and complex explanatory models have been constructed. Such comprehensive models contain a wealth of information but are unwieldy. The use of them is mainly restricted to making simulation runs for evaluating and identifying gaps in our knowledge, for sensitivity analyses, for guiding experiments and for demonstration purposes. Although some of these comprehensive models are well documented and elements out of it are widely used, their use as such is mainly restricted to the group of people that developed the model. This not only restricts their use in practice, but also undermines their credibility. Moreover, credibility may have suffered in the earlier days of modelling from the lack of definition of the purpose of the model and from the incorporation of too much detail.

The lucidity and usefulness of simulation models is sometimes improved by replacing the numerical treatment of the underlying processes by more analytical approaches. A good example of this is the development of multilayer-micrometeorological simulation programmes, as originally conceived by Goudriaan (1 977). In this set of programmes Chen (1 984) rewrote the rather clumsy numerical treatment of the radiation profile as a set of difference equations with vectors as variables and matrices as coefficients. This allowed solutions to be found by standard matrix methods. Another problem of the original model was the simulation of profiles of temperature and humidity, because the equations for the sensible and latent heat flux are coupled and must therefore be solved simultaneously. It appears, however, that both fluxes can be replaced by two other fluxes. The first is the enthalpy flux density, which is the simple sum of the sensible and latent heat flux and is driven by the net radiation absorbed. The second is the saturation heat flux density, which is again the sum of both, but is weighted in such a way that the gradient of the vapour pressure deficit is the driving force. The latter flux is hard to visualize, but the advantage of the approach is that the two new fluxes are independent of each other and that the stomatal resistance has no influence on the enthalpy flux but only on the saturation heat flux. In this way Chen (I984) simplified the treatment to such an extent that a multilayer crop-micrometeorological simulation model could be written in a form that is executable on a microcomputer instead of a main-frame computer, without losing accuracy, flexibility or generality.

Comprehensive, multilayer-micrometeorological models are of special importance in the analyses of the epidemiology of pests and diseases. For crop growth modelling they may be often simplified into double-layer models in which one layer represents the crop and the other the soil surface. In general, it appears that comprehensive crop models themselves may be reduced to summary models that retain much of the scientific base and quality of the original but are much easier to apply by those who did not develop them. 
These summary models differ in principle from earlier and simple preliminary models, although their appearance may be similar. Preliminary models are simple because of incomplete analyses and understanding of the modelled system, while summary models are simple as the result of a conscious and guided reduction process of evaluated and well documented comprehensive models. The simplification often starts with a reduction and better specification of the aims of the model, so that, depending on these, a number of summary models may evolve from one or two comprehensive models, as has been the case in crop production modelling.

\section{HiERARGHICALLY ORDERED PRODUGTION SITUATIONS}

For agricultural production purposes, our modelling activities are centred around several hierarchically ordered production situations (van Keulen \& de Wit I982; van Keulen \& Wolf 1985). In the first production situation water, minerals and nitrogen are in optimal supply. Crop yield is then determined by the type of crop, the radiation receipt and the temperature. The amount of rainfall and its distribution and soil physical and chemical conditions are of no concern. The growth rate of the crop in terms of dry matter amounts to $150-350 \mathrm{~kg} \mathrm{ha}^{-1} \mathrm{~d}^{-1}$ when the canopy fully covers the soil. In practice this situation may be approached on irrigated fields, but in general it is typically an upper standard that can be set.

In the second production situation, growth is limited by water for at least part of the time, but increases to the level set by temperature, radiation and crop cover when optimal water is available. The rainfall pattern and the soil physical properties here often play an important role. This second situation may be approached in practice on non-irrigated, but properly drained and fertilized fields.

In the third production situation, growth is also limited by nitrogen for part of the time, but minerals are still in optimal supply. The organic matter and nitrogen balance, the availability of nitrogen and the crop response to nitrogen are emphasized. This third production situation occurs in many agricultural regions where at least some industrial fertilizers are used.

In the fourth production situation, the growth of the crop is also at times limited by phosphate or other minerals. The soil chemical properties come now to the foreground. This last situation often occurs when few, if any, external inputs are used, as in many forms of subsistence farming. Typical crop growth rates are then around $25 \mathrm{~kg} \mathrm{ha}^{-1} \mathrm{~d}^{-1}$.

Although few cases are found that fit exactly into any one of these four production situations, it is a practical simplification to reduce specific cases to one of them. It focuses attention on the dynamics of the principal environmental factors and on the response of the crop to them. Other environmental factors can then be neglected because they do not affect the growth rate. Growth rate then sets the rate of absorption or the efficiency of use of the non-limiting factor. If for instance, plant growth is limited by nitrogen there is little point in studying the $\mathrm{CO}_{2}$ assimilation and transpiration to understand the current growth rate. Thus, the production situations are hierarchically ordered, with the result that in summary models the outputs of the models for the higher ordered may be used as inputs for the lower ordered ones.

\section{PRODUGTION MODELS}

Given the long-standing continuing interest and research on soil-water relations, potential transpiration and, later, on potential assimilation, it is not surprising that by far the most sophisticated comprehensive models are available for the first and second production situations. 
The summary models that have been developed from these are useful for well defined and limited purposes, such as the prediction of potential yields and their dependence on the rainfall pattern and water supply. They enable an evaluation of the possibilities within a region and the setting of standards for project development (van Keulen \& Wolf r 985). An example is the prediction of potential yields in the Sahel. This was undertaken as part of a research and development project in the region, before the field work was started (Penning de Vries \& van Heemst I 977). These predictions not only proved to be correct, but the framework set by them made the subsequent research effort much more goal-oriented and efficient (Penning de Vries \& Djitéye I982). Models for these two production situations have also been used to estimate food production potentials on a world scale to contribute to the continuing discussion of the future possibilities of food production (de Wit 1967; Buringh et al. 1975).

By far the weakest feature of these production models is the simulation of assimilate partitioning among organs and the response of plants in terms of function and morphology for severe water stress. The only morphogenetic aspects that are modelled in a more or less explanatory fashion are the functional balance between shoot and root growth and the development of sink size for seed growth in wheat. Other aspects of partitioning are treated descriptively, such as distribution patterns in dependence of development stage. This functions rather well in normal conditions but does not deal properly with deviations from the normal pattern when diseases are involved or when weather conditions are extreme. Crop production models are therefore only applied in the predictive mode in situations where it is known that the crop can grow; they are not used to investigate the possibilities in borderline cases. A breakthrough in explanatory modelling of the partitioning of dry matter is badly needed, but can only be expected if there is a renewed interest in morphogenetic problems in the biological sciences (de Wit \& Penning de Vries I983).

Despite these difficulties some practical uses of predictions can be recognized. In crop production models the dependence of final yield on the separate assumptions of the model or its individual parameters can be tested. The assumptions may prove not to be significant and hence not warrant initiation of research in that field, or the opposite. When used in this way, models are then a tool to direct research. Within limits, the potential importance of modifying a certain crop characteristic can be tested before direct breeding is undertaken. An example is the exploration of the importance of selection and breeding of lines with lower maintenance respiration, the existence of which has recently been demonstrated (Wilson \& Jones 1982). Weather patterns may be imposed on models in studies of the stability of yields of new crop varieties or of crops in new areas that are not too different from existing ones. In this way, modelling can shorten an experimental programme that otherwise requires many years. Lastly, prediction of yield only a few weeks ahead of time, or even in retrospect, can be of use to industry or trade. The sugar beet industry, for instance, is interested in yield predictions even if they are made less than thirty days before the harvest. This is because other methods of estimating harvest are slow and costly. Dutch bulb traders know at an early stage the acreage of tulip varieties planted in any year. The yields of the July harvest are known only shortly before the next Ghristmas. But by then most of the selling to the best markets has finished so that this information is only of historical interest.

For the third production situation, in which nitrogen is at times limiting, comprehensive models of the organic matter and nitrogen balance and turnover have been developed. These models have a well developed theoretical basis, but their current usefulness is restricted by lack of data for the many model parameters and by difficulties with defining initial values of the 
state variables. The evaluation of these comprehensive models thus presents great problems. Nevertheless, summary models are being developed on the basis of the comprehensive models in combination with field experimentation, which can be used for predictive purposes. The state of the art in this respect is reflected very well in a Danish simulation model (Hansen \& Aslyng I984).

In spite of the long history of research in soil chemistry, only preliminary models are available for the fourth production situation in which minerals and especially phosphate are at times limiting. This reflects partly the complexity of the chemistry of the soil. In addition the need for a model is not urgent because the classical approach of soil analyses in combination with simple fertilizer experiments continues to give satisfactory results in practice.

\section{WEEDS, PESTS AND DISEASES}

Weeds, pests and diseases may occur in any production situation. Well verified comprehensive models have been developed for epidemics of pests (aphids), diseases (rusts) and weeds (annuals) (Rijsdijk 1985; Rabbinge 1982; Rabbinge \& Carter 1983). These have drawn attention to the fact that damage depends very much on the production situation. As a result of an increased competitive ability of the crop, damage by weeds may decrease relatively with increasing yields. For aphids the reverse is true because the value of the host plant as a source of food to the aphids increases with increasing yield level.

Summary models have been developed for damage control management on a field by field basis. From every field basic data are stored in a data bank. Farmers send in their field observations from which the basic field data are updated by means of summary models. Expected damage and loss are calculated and used in a decision system that leads to one of three decisions; 'treat', 'do not treat', or 'make another round of field observations at some later, specified date'.

Such a system has been developed in the Netherlands and has been adopted by the Extension Service, which charges the farmer at present about half of the operating costs involved. All evidence suggests that these supervised disease, pest and weed management systems are gaining in importance.

\section{Conclusion}

Prediction has been redefined as organized thinking about the possible and it is within this context that dynamic simulation models are emerging as tools for the management of crops to permit greater efficiency in production and management. The development of these new tools requires hard work and patience and they certainly will not meet the goals that are set for them by critics who disclaim their usefulness. However, it has now been shown that the use of these explanatory dynamic simulation models results in so many advantages once their value is established, that they will continue to be developed in the new decade.

\section{REFERENGES}

Buringh, P., van Heemst, H. D. J. \& Staring, G. J. 1975 Computation of the absolute maximum food production of the world. (59 pages.) Department of Tropical Soil Science, Agricultural University, Wageningen.

Ghen, J. 1984 Mathematical analyses and simulation of crop micrometeorology. Ph.D. thesis, Agricultural University, Wageningen, The Netherlands.

Goudriaan, J. I977 Crop micrometeorology: a simulation study. Ph.D. thesis, Simulation Monographs, Pudoc, Wageningen, The Netherlands. 
Hansen, S. \& Aslyng, H. G. 1984 Nitrogen Balance in Crop Production. Simulation model NITCROS. (113 pages.) Hydro-Technical Laboratory, Royal Veterinary and Agricultural University of Copenhagen.

van Keulen, H. \& Wolf, J. (eds) I985 Modelling of agricultural production: weather, crops and soils. Simulation Monographs, Pudoc, Wageningen, The Netherlands. (In the press.)

van Keulen, H. \& de Wit, C. T. I982 A hierarchical approach to agricultural production modeling. In Modeling agricultural-environmental processes in crop production (ed. G. Gobulev \& I. Shvytov), pp. 139-153. IIASA symposium, Laxenburg.

Monteith, J. L. I98I Climate variation and the growth of crops. Q. Jl R. met. Soc. 107, 743-774.

Penning de Vries, F. W. T. \& Djiteye, M. A. (eds) 1982 La productivité des pâturages sahéliens - une étude des sols, des végétations et de l'exploitation de cette ressource naturelle. Pudoc, Wageningen, The Netherlands.

Penning de Vries, F. W. T. \& van Heemst, H. D. J. 1977 Potential primary production of unirrigated land in the Sahel. In Evaluation and mapping of tropical African rangelands. Proceedings of the Seminar, Bamako, Mali, 3-8 March, pp. 323-327. Addis Ababa, ILGA.

Penning de Vries, F. W. T. \& van Laar, H. H. (eds) 1982 Simulation of plant growth and crop production. (308 pages.) Simulation Monographs, Pudoc, Wageningen, The Netherlands.

Rabbinge, R. \& Carter, N. 1983 Application of simulation models in the epidemiology of pests and diseases: an introductory review. Bulletin IOBC/WPRS, New Series, VI (2), pp. 18-30.

Rabbinge, R. 1982 Pests, diseases and crop production. In Simulation of plant growth and crop production (ed. F. W. T. Penning de Vries \& H. H. van Laar). (308 pages.) Simulation Monographs, Pudoc, Wageningen, The Netherlands.

Rijsdijk, F. 1985 Weeds, Pests and Diseases. In Modelling of agricultural production: weather, soils and crops (ed. H. van Keulen \& J. Wolf). Simulation Monographs, Pudoc, Wageningen, The Netherlands. (In the press.)

Wilson, D. \& Jones, J. G. 1982 Effects of selection for dark respiration of mature leaves on crop yields of Lolium perenne cv S23. Ann. Bot. 3, 313-323.

de Wit, C. T. I967 Photosynthesis: its relationship to over-population. In Harvesting the sun, IMC-symposium, Chicago, 1966 (ed. A. San Pietro, F. A. Greer \& T. J. Army).

de Wit, C. T. \& Penning de Vries, F. W. T. 1983 Crop growth models without hormones. Neth. J. agric. Sci. 31, $313-323$.

de Wit, G. T. 1974 Early concepts in soil fertility. Neth. J. agric. Sci. 22, 319-324.

de Wit, C. T. 1970 Prediction and measurement of photosynthetic productivity. Proceedings of the IBP/PP Technical Meeting, Trebon, 14-21 September 1969 (ed. I. Šetlík), pp. 17-23.

\section{Discussion}

J. V. LAKe (Agricultural and Food Research Council, Letcombe Laboratory, Wantage, Oxon OX12 9JT). Dr Penning de Vries has mentioned the potential usefulness of mathematical models in providing the farmer with management advice, for example, about the use of nitrogen fertilizers during a crop growing season. Does he agree that with the rapid development of new transducers and associated microprocessors, on-line monitoring of crop growth and environment should allow continuing updating and improvement of the model while it is in use, leading to much improved accuracy? Increasingly, information so gathered from practical agriculture may perhaps be used by scientists to verify their hypotheses and the need for factorial field experiments as we know them may gradually decrease.

F. W. T. Penning De VRies. For further development of such models it will be very helpful to have better ways of measuring key state variables in the crop and in the soil. Reliable and quick measurements of such variables will be indispensable once the models are established and used for providing farm management advice. However, we still face two questions that are of a scientific rather than a technological nature: (i) which exactly are those key variables and when exactly are they to be determined and (ii) how to cope with the spatial heterogeneity of soil and crop. 